\title{
Compression garments to prevent delayed onset muscle soreness in soccer players
}

\author{
Xavier Valle $e^{1,2,3}$ \\ Lluís Til ${ }^{1,4}$ \\ Franchek Drobnic ${ }^{1,4}$ \\ Antonio Turmo 2,4 \\ José Bruno Montoro 5 \\ Oliver Valero 6 \\ Rosa Artells ${ }^{7}$
}

1 F.C. Barcelona Medical Services, Barcelona, Spain

2 Sports Medicine School, University of Barcelona, Spain

${ }^{3}$ Clinica Mapfre de Medicina del Tenis, Barcelona, Spain

${ }^{4}$ CAR of Sant Cugat-Consorci Sanitari de Terrassa, Barcelona, Spain

5 Faculty of Pharmacy, University of Barcelona, Spain

6 Servei d'Estadística, Universitat Autònoma de Barcelona, Spain

7 Human Anatomy and Embriology Unit, School of Medicine, University of Barcelona, Spain

\author{
Corresponding author: \\ Xavier Valle \\ Medical Department F.C. Barcelona \\ $\mathrm{C} /$ Arístides Maillol, S/N \\ CP 08028 Barcelona, Spain \\ E-mail: xavier.valle@fcbarcelona.cat
}

\section{Summary}

The purpose of this study was to evaluate the use of a compression garment as DOMS prevention. This was accomplished by provoking a DOMS in 15 athletes, running on a treadmill at $73 \%$ of their maximal aerobic velocity, during $\mathbf{4 0}$ minutes with a $10 \%$ negative slope; wearing the compression garments on one thigh, protected thigh (PT), and not in the contralateral thigh, control thigh (CT).

A clinical and MRI diagnosis of DOMS was performed. Biopsies in both vastus lateralis were done, and the amount and severity of the DOMS was estimated by measuring intracellular albumin, and lymphocytes CD3+ and neutrophils intra/interfibrilar infiltrates, $48 \mathrm{~h}$ after the induced damaging exercise.

There was less total injury in the PT than in the CT, a $26.7 \%$ average. These data indicate that this compression garment is an effective method to reduce the histological injury in DOMS.
KEY WORDS: albumin, biopsy, eccentric, inflammatory cells, muscle.

\section{Introduction}

Delayed onset muscle soreness (DOMS) ${ }^{1}$ is the discomfort and pain while the muscle contracts, it appears after doing unusual exercise, and normally although not exclusively, related to eccentric muscular work ${ }^{2,3}$. Muscle soreness is accompanied by a feeling of stiffness as a result of muscle oedema ${ }^{4}$, as well as a loss of strength and range of movement $(\mathrm{ROM})^{5,6}$ The signs and symptoms begin between 6-12 $\mathrm{h}$ after exercise, increase progressively until reaching a peak pain between 48-72 $\mathrm{h}$, and reduce until they disappear between 5-7 days later 2,7,8. DOMS is also accompanied by biochemical alterations like an increase of CPK in the blood ${ }^{9}$. In some studies it is classified as a muscle injury grade $1^{10}$, although its clinical evolution is different ${ }^{1,11}$. In fact, it has been used as an experimental model to study the muscle injury ${ }^{12}$.

Compression garments as a therapeutic or preventative measure, are normally used in different scopes of medicine (vascular pathology, plastic surgery, in sports medicine). Multiple articles have appraised the effect of the compressive garments on muscle function $^{12-23}$ recovery post exercise ${ }^{24-29}$, motor control ${ }^{30}$, thermoregulation ${ }^{31}$, warming $\mathrm{up}^{17}$ and $\mathrm{ROM}^{17,32}$. Compression garments for DOMS recovery have also been studied by applying compression measures after the bout of exercise ${ }^{27,33-36}$, however, the compression garments assessed are made of distinct materials and they differ in composition, architecture or degree of compression, making difficult to compare results. Moreover, compression garments have not been studied as a preventative strategy during provocation.

Signs of histological muscle damage in DOMS are myofibrillar structure disruptions and myofibre necrosis and inflammation ${ }^{37}$. Sarcolemmal membrane injury allows extracellular proteins like albumin to be detected intracellular, this is a sign of membrane injury ${ }^{38,39}$.

The inflammatory reaction within myofibres is a sign of segmental myofibre degradation and necrosis, neutrophils (MPO) and lymphocytes CD3+ (CD3+) reflect the amount and intensity of cellular damage ${ }^{37,40}$.

Thus, the aim of this study is to evaluate if there is a protective effect of compression against DOMS; more specifically, the protective effect of this compression garments against DOMS. For this purpose we will evaluate the amount of damaged fibbers and the severity of this damage by measuring intracellular albumin, lymphocytes CD3+ $(C D 3+)$ and neutrophils 
(MPO) intra/interfibrilar infiltrates, after the induced damaging exercise.

\section{Methods}

\section{Experimental approach to the problem}

An experimental, prospective study, involving healthy athletes with no clinical history of interest, and who regularly did physical activity, was designed. Each individual served as own control, since one thigh wore the compression garment, protected thigh (PT), while the other remained unprotected, control thigh (CT), Figure 1.

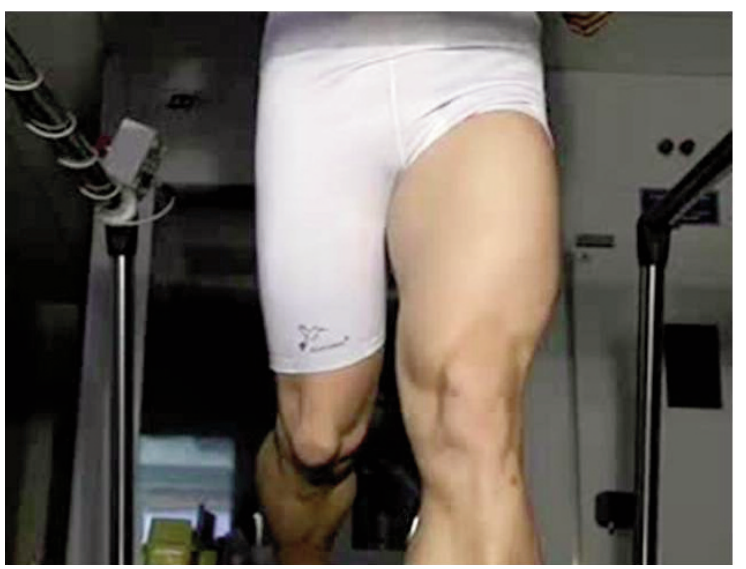

Figure 1. Right tight protected and left without compression garment.

\section{Subjects}

Adult male amateur soccer players from two different local clubs, older than 18 years, with a regular training activity from 4-12 hours per week during at least 3 months, were considered to take part in the study. Three weeks before the study they were instructed to eat normally, and to avoid: unusual physical activity, alcohol, and any toxic substances until the end of the study. Neither did they have any medical or pharmacological (NSAID, analgesic) treatment, or any physical measurement that could alter the result of the injury (cryotherapy, warm baths, massage, electrotherapy, etc.).

Previous to the inclusion, the subjects were informed about the protocol and its objectives and gave their consent to take part in the study. The project was previously assessed and approved by the ethics committee of the Consell Català de l'Esport (0099S/ 4882/2010). Sixteen individuals were initially included in the study; nevertheless, the final sample was 15 because one of the subjects could not complete the study. The main physical and physiological baseline characteristics of the subjects evaluated are shown in Table 1. Additionally, the distribution of the subjects leg dominance, together with randomization for the compression, are shown in Table 2. Athletes were allocated in the right or left thigh compression group following a randomization process by taking random numbers from a com- puter program, a summary of the protocol is shown in Figure 3A, and the flow Diagram Figure 3B.

\section{Procedures}

Compression tights: the compression tights used in the study (Colibri ${ }^{\circledR}$, Puntiblond, Spain) are made of a combination of a compression fabric (polyamide 57\% and elastomer $43 \%$ ), with inner reinforcements over the quadriceps and hamstrings, Figure $2 \mathrm{~A}$ and $\mathrm{B}$. The tights composition and its $3 \mathrm{D}$ structure allow it to control the elasticity at $360^{\circ}$, Figure $2-C^{41}$. The level of compression was not measured, all subjects used the smaller size garment they could wear, and the choice of size was performed under the supervision of the authors.

Submaximal test and bout of eccentric exercise: nine days before the DOMS provocation, each subject performed an incremental submaximal exercise test on a motorised treadmill (EG2, Vitoria, Spain), oxygen consumption was measured using a computerised metabolic cart (Master Screen CPX, Erich Jaeger, Wuerzburg, Germany). The test protocol start 3 minutes at $8 \mathrm{~km} / \mathrm{h}$ with $3 \%$ of positive slope, and then 1 $\mathrm{km} / \mathrm{h}$ speed increases every minute until to reach the $90 \%$ of the theoretical maximal heart rate. The test was used to determinate the subject's speed for the DOMS provocation exercise.

The bout of eccentric exercise started with $10 \mathrm{~min}$ utes running at free speed on a treadmill (EG2, Vito-

Table 1. Descriptive statistics, patient and test variables. MAP: Max. Aerobic Power, MAV: Max. Aerobic Velocity, MV: Max. Velocity, AnTV: Anaerobic Threshold Velocity. *: Median (Min-Max).

\begin{tabular}{lll}
\hline & \multicolumn{3}{l}{ Mean } \\
\hline Age (years) & 25.0 & $(19-50)^{*}$ \\
Height $(\mathrm{cm})$ & 177.6 & $(3.3)$ \\
Weight $(\mathrm{kg})$ & 78.2 & $(5.8)$ \\
BMI $\left(\mathrm{Kg} / \mathrm{m}^{2}\right)$ & 24.7 & $(1.6)$ \\
MAP $(\mathrm{ml})$ & 3433 & $(594)$ \\
MAV $(\mathrm{km} / \mathrm{h})$ & 13,9 & $(1,7)$ \\
VO2 $\mathrm{mL} /\left(\mathrm{kg}{ }^{*} \mathrm{~min}\right)$ & 44.0 & $(7.6)$ \\
MV $(\mathrm{km} / \mathrm{h})$ & 13.8 & $(1.7)$ \\
AnTV $(\mathrm{km} / \mathrm{h})$ & 11.2 & $(1.9)$ \\
VO2Ua $(\mathrm{ml})$ & 2768 & $(588)$ \\
Heart Rate $(\mathrm{bpm})$ & 163 & $(11.7)$ \\
Test Velocity $(\mathrm{km} / \mathrm{h})$ & 10.7 & $(1.7)$ \\
\hline
\end{tabular}

Table 2. Treatment randomization results, according to leg characteristics. R: Right, L: Left.

\begin{tabular}{llll}
\hline & \multicolumn{2}{l}{ Dominant Leg } & \\
\cline { 2 - 3 } & $\mathrm{R}$ & $\mathrm{L}$ & Total \\
\hline Compression R & $6(50 \%)$ & $1(33 \%)$ & $7(47 \%)$ \\
Compression L & $6(50 \%)$ & $2(67 \%)$ & $8(53 \%)$ \\
Total & 12 & 3 & 15 \\
\hline
\end{tabular}


ria, Spain), as a warm up, and without stop, 40 minutes with a $10 \%$ downhill slope, at $73 \%$ of the maxi-

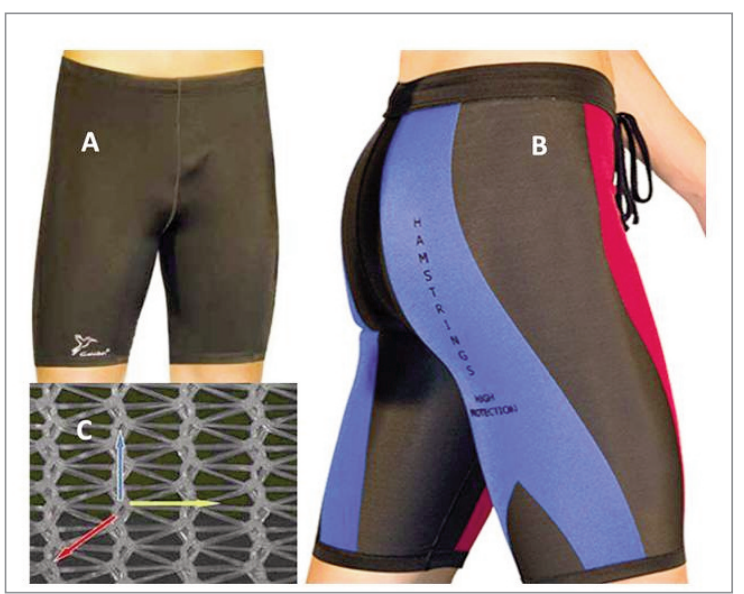

Figure 2. Compression garment, A: external surface, B: internal surface, C: fabric architecture.

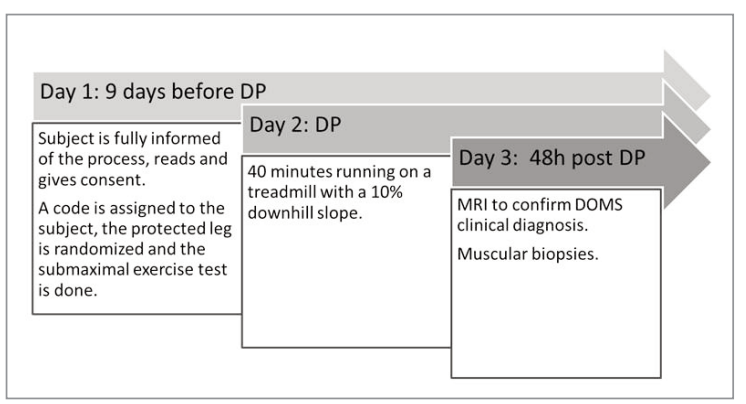

Figure 3A. Study protocol. DP: DOMS provocation. mum speed reached in a submaximal test, done nine days before. Randomly, the subjects wore the compression garment on one thigh, the PT group, while the other thigh was cut and left unprotected, the CT group ${ }^{32}$.

DOMS Evaluation: an initial clinical diagnosis of DOMS, was confirmed by performing a magnetic resonance imaging $(\mathrm{MRI})^{42}$. The degree of histological injury was assessed by taking a biopsy of the vastus lateralis of both thighs and measuring, intracellular albumin, and CD3+ and MPO intra/interfibrilar infiltrates, $48 \mathrm{~h}$. after the bout of eccentric exercise.

MRl: a high magnetic field system was used (Signa 1.5 T G.E. Milwaukee). The patients were placed in the supine decubitus position and entered the exploration tunnel head first. Both thighs were explored with a coil body. The diagnosis was carried out looking for alterations in the MRI signal in any muscular group both in the flexor compartment and the extensor and its asymmetry as regards the contralateral homonymous muscular group. When the radiologist read the results he did not know which thigh was protected with the tight being studied 22 .

Biopsies: the biopsies were obtained using a Vacora System Biopsy pistol (Bard), with a coaxial needle of $10 \mathrm{G} \times 140 \mathrm{~mm}$. With this technique the sample is aspirated and remains in the branula until it is extracted; the sample is taken out as a whole and not fragmented. Two biopsies were carried out from the middle third of each vastus lateralis, under ultrasound control. Previously, a cutaneous incision was performed with a $5 \mathrm{~mm}$ blade, the entrance was the same for both biopsies but the needle direction was modified ${ }^{6,22,42}$. Once the samples were extracted, they were kept in formol, glutaraldehyde and a third sample was cryopreserved at $-80^{\circ} \mathrm{C}$ for further studying ${ }^{43}$.

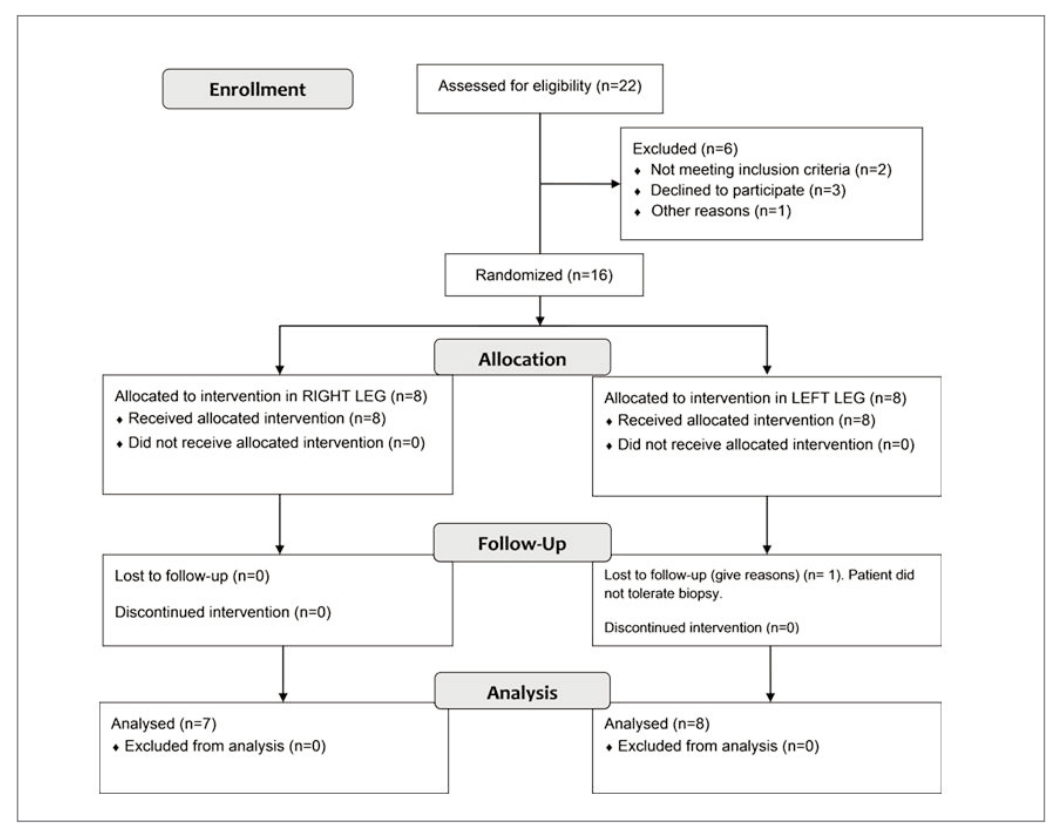

Figure 3B. Flow diagram. 
Sarcolemmal disruptions evaluation: cellular membrane permeability to albumin is a sign of membrane injury ${ }^{37}$. For hystochemical procedures, all muscle specimens were first dissected free of visible connective tissue and fat and embedded in paraffin using conventional methods ${ }^{46}$. Ten-micrometre sections were cut, varying the inclination of the holder by 5 degree increments until the minimum cross-sectional area was obtained, which was defined as truly transverse. For assessment and quantification of muscle membrane injury we chose a method based on light microscopy for identification of fibers that contain albumin by immunohistochemistry. Each sample was processed for immunohistochemical techniques using a polyclonal rabbit anti-human antibody directed against albumin (Code No. A0001; Dako Cytomation, DK-2600 Glostrup, Denmark) as a primary antibody. This immunocomplex was detected using a horseradish peroxidase-labeled goat antirabbit secondary antibody (Code No. K4003; EnVision+System-HRP labelled polymer, Dako Co., Carpinteria, CA, USA). The reaction was developed with a chromogen solution with 3.3-diaminobenzidine (Code No. K3468; Liquid DAB+ Substrate-Chromogen Solution, Dako Co., Carpinteria, CA, USA). The analysis of intracellular albumin was performed by two independent observers using a categorical scale (0-3) with a light microscope (Olympus, Series AX70TF; Olympus Optical Co., Shinjukuku, Tokyo, Japan) coupled with an image-digitizing camera (View Finder Lite; Version 1.0.143c; Pixera Co., Los Gatos, CA) and a morphometry program (Scion Image, Version Beta 4.0.2; Scion Co., Frederick, MD, USA). Qualification of fiber injury was performed in a four-category finite interval system, the extremes representing either the absence of intracellular albumin (i.e., absence of sarcolemmal injury, degree 0), or presence of intracellular albumin on the complete cellular area (i.e., severe sarcolemmal injury, degree $3)$, Table 3. The two intermediate categories were determined by degree 1 injury (i.e., mild sacolemmal injury or presence of albumin in less than $50 \%$ of the fiber area) and degree 2 injury (i.e., moderate sarcolemmal injury or presence of albumin on more than $50 \%$ of the fiber area, but not in all of it). Fiber categories were expressed as proportion (\%) of total muscle fibers. The mean value of degree 2 and degree 3 obtained by two observers was used for statistical analysis 44,45 .

Table 3. Fiber injury degrees description.

\begin{tabular}{|c|c|}
\hline Degree & Description \\
\hline 0 & Absence of intracellular albumin. \\
\hline 1 & $\begin{array}{l}\text { Presence of albumin in less than } 50 \% \\
\text { of the fiber area. }\end{array}$ \\
\hline 2 & $\begin{array}{l}\text { Presence of albumin on more than } \\
50 \% \text { of the fiber area, but not in all of it. }\end{array}$ \\
\hline 3 & $\begin{array}{l}\text { Presence of intracellular albumin on the } \\
\text { complete cellular area. }\end{array}$ \\
\hline
\end{tabular}

CD3+ and MPO Immunohistochemical staining: for assessment and quantification of $\mathrm{CD} 3+$ and MPO intra/interfibrilar infiltrates we chose a method based on light microscopy for identification of $\mathrm{CD} 3+$ and $\mathrm{MPO}$ by immunohistochemistry.

For the immunohistochemical assay we used manual immunostaining. For MPO with a polyclonal rabbit antihuman antibody directed against MPO (Dako Ref. IS511, 1:4 dilution, prediluted), and for CD3+ a polyclonal rabbit anti-human directed against CD3+ (Dako Ref. A0452, 1:250 dilution), used as a primary antibodies.

For MPO antigen retrieval the sections were deparaffinized, rehydrated in gradually decreasing concentrations of ethanol, PBS (3x5'), citrate 7,3 retrieval, pressure cooker, PBS (3x5'), hydrogen peroxide 10' at room temperature, PBS $\left(3 \times 5^{\prime}\right)$, primary antibody $30^{\prime}$ at room temperature 1:4 dilution, PBS $\left(3 \times 5^{\prime}\right)$, secondary antibody Envison 30' at room temperature, PBS (3x5'), DAB (1 drop for $1 \mathrm{ml}$ dilute) $5 / 10$ minutes at room temperature, PBS ( $\left.3 \times 5^{\prime}\right)$, Mayer haematoxylin $10^{\prime}$ at room temperature, water, dehydration, D.P.X. assembly, visualization with Envison/HRP Dako (Glostrup, Denmark).

For CD3+ antigen retrieval the sections were deparaffinized, rehydrated in gradually decreasing concentrations of ethanol, PBS $\left(3 \times 5^{\prime}\right)$, citrate 7,3 retrieval, pressure cooker, PBS ( $\left.3 \times 5^{\prime}\right)$, hydrogen peroxide $10^{\prime}$ at room temperature, PBS $\left(3 \times 5^{\prime}\right)$, primary antibody $30^{\prime}$ at room temperature 1:250 dilution, PBS (3x5'), secondary antibody Envison 30' at room temperature, PBS ( $\left.3 \times 5^{\prime}\right)$, DAB ( 1 drop for $1 \mathrm{ml}$ dilute) 5/10 minutes at room temperature, PBS $\left(3 \times 5^{\prime}\right)$, Mayer haematoxylin $10^{\prime}$ at room temperature, water, dehydration, D.P.X. assembly, visualization with Envison/HRP Dako (Glostrup, Denmark).

The lymphocytic infiltrates (CD3+) and MPO were quantified following the total number of $T$ cells immunostained antibodies against CD3+, and MPO. The total number of CD3+ cells, and the total number of fibres were counted blindly by two observers, and was used for statistical analysis. CD3+ cells per fibre was calculated and compared between PT and $\mathrm{CT}^{40}$. Number of fibres with MPO was evaluated in the same way ${ }^{47,48}$.

The samples were blinded to the laboratory and the statistical analysis, coded with numbers and letters to identify patients and treatment allocation.

\section{Statistical Methods}

Initially a descriptive analysis was performed that includes: summary tables with mean, median and standard deviation were obtained for baseline variables (Age, Height, Weight, BMI, Max. Aerobic Power, VO2 $\mathrm{ml} /\left(\mathrm{kg}^{\star} \mathrm{min}\right)$, Max. Velocity, Anaerobic Threshold Velocity, VO2Ua, Max. Aerobic Velocity, Heart Rate and Test velocity).

Biopsy results, total injury, intracellular albumin, CD3+, MPO and CD3+, of each thigh (control vs. protected), were compared, bivariate analysis was done using the Student-Fisher t-test for paired data or the Wilcoxon 
non-parametric test for non-normal distributions. The assumption of normality was verified using the Shapiro-Wilk test. Means of the differences with its 95\% confidence intervals (IC95\%) were calculated. The results of the subjects' thighs were graphically represented in a scatter plot for a better visualization of the data.

In order to analyse the variables of the biopsy adjusting for patient's characteristics and stress test generalised linear models ${ }^{49}$ were used. A normal distribution was considered for Total injury, a Multinomial distribution for intracellular albumin, and a Poisson distribution for CD3 and MPO. Covariates were recorded in two categories using the median as cutting point. Covariates included in the final model were obtained using a backward stepwise selection method (variables that were not statistically significant were removed from the model).

The analysis was performed with commercially available software (SAS v9.2, SAS Institute Inc., Cary, NC, USA), and the significant level was set to 0.05 .

\section{Results}

Total injury (degrees 1, 2 and 3 together) value were 43.8 (24.93) and 71.81 (23.78) for PT and CT, respectively $(P=0.0016)$, and the mean difference within individuals was $26.7(\mathrm{Cl}, 12.4-41.1)$, Table 4. The concrete values for total injury for each subject, considering separately the PT and CT thighs, are shown in Figure 4.

The values of each subject were, according to their treatment, $75.32 \%$ and $67.59 \%$ higher in CT compared with $\mathrm{PT}$, for CD3+ and MPO infiltrates, respec- tively. Intracellular albumin infiltrate, in absolute value, was also $32.77 \%$ higher in CT. Total inflammatory cells infiltrate were, thus, $72.07 \%$ higher in CT vs. PT. The mean value for intracellular albumin was 1.6 $(0.85)$ and $2.38(0.74)$ for $\mathrm{PT}$ and $\mathrm{CT}$, respectively $(\mathrm{P}$ $=0.0045)$. Within individuals, the mean difference found was $-0.85(\mathrm{Cl}, 0.32-1.38)$. MPO mean value was 1.17 (1.40) and 3.61 (4.00) for PT and CT subjects, respectively $(P=0.001)$, being the mean difference within individuals $2.56(\mathrm{Cl}, 0.46-4.67)$. Similarly, intracellular CD3+ mean value was $0.57(0.73)$ and 2.31 (3.11) for PT and CT, respectively $(P=0.0313)$, and the mean difference $1.88(\mathrm{Cl}, 0.04-3.73)$, Table 5. When albumin infiltrates and injury degree were evaluated, CT group has more degree 1,2 and 3 injury than PT: $11.29 \%, 41.18 \%$ and $54.24 \%$ respectively; conversely, PT has more degree 0 (no injury), than CT, $70.13 \%$. The total injury was higher in CT vs PT, $39.01 \%$, Figure 5.

The variability between individuals can be explained by some of the variables of the patient or the test. Thus, the total injury infiltrate was greater when the subject did the test at higher speeds. Subjects who did the test at more than $10 \mathrm{~km} / \mathrm{hr}$, had $31 \%$ more injury, both in the PT and CT groups, while those who did the test at lower intensities $<1 \mathrm{~V}-\%$ Uan, had $21 \%$ less injury in both groups. After adjusting for these two variables the difference between the $\mathrm{PT}$ and the CT group was 31\% $\left(\mathrm{IC}_{95 \%}=15.4\right.$ - 43.8).

The same happened with the MPO infiltrate. The subjects who did the test at more than $10 \mathrm{~km} / \mathrm{hr}$ and those who did it at $1 \mathrm{~V} . \%$ Uan, had 4 times more injury. After adjusting for these variables, the CT group results showed $3.3\left(\mathrm{IC}_{95 \%}=1.98-5.47\right)$ times more injury than the PT.

Table 4. T In: Total Injury, In 0-3: Injury degree 0-3, Dif.: Difference, SD: Standard Deviation.

\begin{tabular}{|c|c|c|c|c|c|c|c|c|c|c|c|}
\hline & Group & Mean & Median & SD & Min. & Max. & Dif. & $\%$ Dif. & \multicolumn{2}{|l|}{$\mathrm{IC}_{95 \%}$} & $p$-value \\
\hline \multirow{2}{*}{$\ln 0$} & PT & 50,12 & 56,69 & 28,27 & 0 & 100 & \multirow{2}{*}{$-22,76$} & \multirow{2}{*}{$-70,13$} & \multirow{2}{*}{$-35,38$} & \multirow{2}{*}{$-10,14$} & \multirow{2}{*}{0,0022} \\
\hline & $\mathrm{CT}$ & 29,46 & 30,5 & 24,38 & 0 & 77 & & & & & \\
\hline \multirow{2}{*}{$\ln 1$} & PT & 28,22 & 25 & 16,14 & 0 & 62,04 & \multirow{2}{*}{3,05} & \multirow{2}{*}{11,29} & \multirow{2}{*}{$-12,18$} & \multirow{2}{*}{18,28} & \multirow{2}{*}{0,662} \\
\hline & $\mathrm{CT}$ & 31,81 & 34,5 & 14,33 & 2,85 & 52 & & & & & \\
\hline \multirow{2}{*}{$\ln 2$} & PT & 15,67 & 11,74 & 15,07 & 0 & 57,78 & \multirow{2}{*}{11,78} & \multirow{2}{*}{41,18} & \multirow{2}{*}{2,08} & \multirow{2}{*}{21,48} & \multirow{2}{*}{0,0217} \\
\hline & $\mathrm{CT}$ & 26,64 & 23 & 16,07 & 8 & 54,29 & & & & & \\
\hline \multirow{2}{*}{$\ln 3$} & PT & 5,99 & 2,56 & 9,27 & 0 & 32,14 & \multirow{2}{*}{8,57} & \multirow{2}{*}{54,24} & \multirow{2}{*}{$-0,2$} & \multirow{2}{*}{17,34} & \multirow{2}{*}{0,0137} \\
\hline & $\mathrm{CT}$ & 13,09 & 9 & 12,5 & 3 & 42,86 & & & & & \\
\hline \multirow{2}{*}{$T \ln$} & PT & 43,8 & 42 & 24,93 & 0 & 96,67 & \multirow{2}{*}{26,7} & \multirow{2}{*}{39,01} & \multirow{2}{*}{12,36} & \multirow{2}{*}{41,05} & \multirow{2}{*}{0,0016} \\
\hline & $\mathrm{CT}$ & 71,81 & 71 & 23,78 & 23 & 100 & & & & & \\
\hline
\end{tabular}


The differences between the values of intracellular albumin and CD3+ can only be explained due to the treatment (there are no significant statistical differences in the variables of the patient or the test).

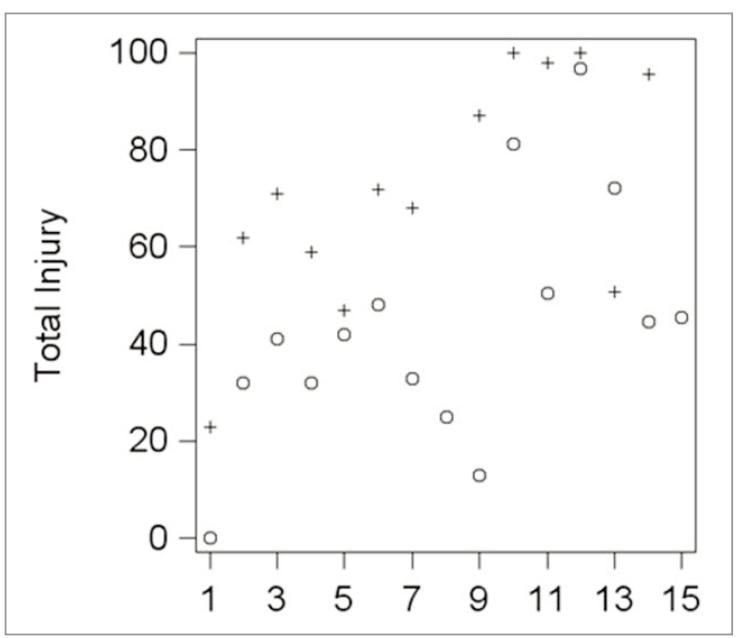

Figure 4. Scatter plots of the biopsy results for each subject. + (Control), o (Treatment).

\section{Discussion}

Many studies have evaluated the use of preventative and therapeutic measures against DOMS, but only a single reference exists - the repeated bout effect with scientific evidence ${ }^{50}$. Moreover, several studies involving different compression garments used in the DOMS treatment ${ }^{27,33-36}$ have been described, but none of them as a preventative measure.

Even being a common problem in sports medicine research, we know the sample in our study should be bigger, but is not easy to find athletes with good athletic level wanting to participate in studies, this were one of the reasons we decided to use the subject as his own control. Obviously the major part of the people was right-hand, only three subjects were left-hand in our study, and we did not find relation between the dominant hand and the amount of injury in our data analysis.

The effects of the compression tights (Colibri ${ }^{\circledR}$, Puntiblond, Spain), on the biomechanics of running, high jump and tissue oscillation during intense exercise have been evaluated previously in different studies. It has been observed that the use of this garment produces a minimum decrease in hip and knee ROM without affecting the frequency and length of the

Table 5. Ic Alb: Intracellular Albumin (Absolute Value), CD3: Intra/interfibrilar CD3 infiltrate, MPO: Intra/interfibrilar Neutrophils infiltrate, TIC: Total Inflammatory cells (CD3+MPO), Dif.: Difference, SD: Standard Deviation.

\begin{tabular}{|c|c|c|c|c|c|c|c|c|c|c|c|}
\hline & Group & Mean & Median & SD & Min. & Max. & Dif. & $\%$ Dif. & \multicolumn{2}{|c|}{$\mathrm{IC}_{95 \%}$} & $\mathrm{p}$-value \\
\hline \multirow{2}{*}{ Ic Alb } & PT & 1,6 & 1,5 & 0,85 & 0 & 3 & \multirow{2}{*}{0,85} & \multirow{2}{*}{32,77} & \multirow{2}{*}{0,32} & \multirow{2}{*}{1,38} & \multirow{2}{*}{0,0045} \\
\hline & $\mathrm{CT}$ & 2,38 & 2,5 & 0,74 & 1 & 3 & & & & & \\
\hline \multirow{2}{*}{ CD3 } & $\mathrm{PT}$ & 0,57 & 0 & 0,73 & 0 & 2 & \multirow{2}{*}{1,88} & \multirow{2}{*}{75,32} & \multirow{2}{*}{0,04} & \multirow{2}{*}{3,73} & \multirow{2}{*}{0,0313} \\
\hline & $\mathrm{CT}$ & 2,31 & 1 & 3,11 & 0 & 11 & & & & & \\
\hline \multirow{2}{*}{ MPO } & PT & 1,17 & 1 & 1,21 & 0 & 4 & \multirow{2}{*}{2,56} & \multirow{2}{*}{67,59} & \multirow{2}{*}{0,46} & \multirow{2}{*}{4,67} & \multirow{2}{*}{0,001} \\
\hline & CT & 3,61 & 2 & 4 & 0 & 12 & & & & & \\
\hline \multirow{2}{*}{ TIC } & PT & 1,74 & 1,5 & 1,4 & 0 & 5 & \multirow{2}{*}{4,73} & \multirow{2}{*}{72,07} & \multirow{2}{*}{1,52} & \multirow{2}{*}{7,93} & \multirow{2}{*}{0,001} \\
\hline & $\mathrm{CT}$ & 6,23 & 5 & 5,43 & 1 & 18 & & & & & \\
\hline
\end{tabular}
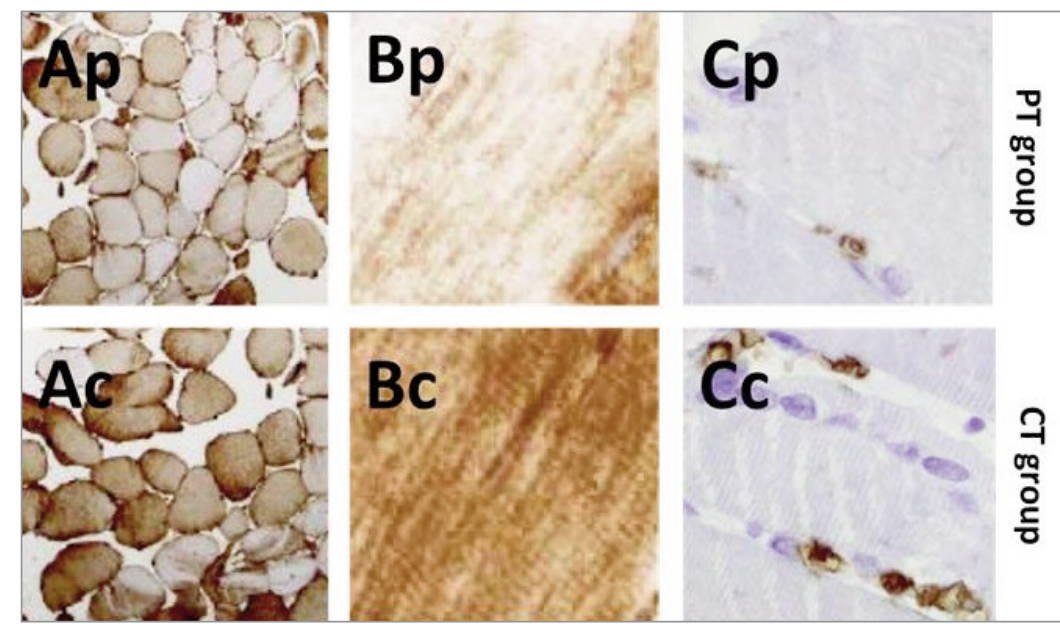

Figure 5. Biopsies. Ap: Albumin infiltrate, transversal section (PT), Ac: Albumin infiltrate, transversal section (CT). Bp: Albumin infiltrate, longitudinal section (PT), Bc: Albumin infiltrate, longitudinal section $(\mathrm{CT}), \mathrm{Cp}$ : CD3 infiltrate (PT), Cc: Cd3 infiltrate (CT). 
stride, without affecting the efficiency of running ${ }^{51}$; that performance in high jump is not modified ${ }^{41}$; and the amount of the inherent muscular oscillation in the race is smaller in the protected compression thigh 52 .

The reduction in muscle oscillation is related to an improvement in neurotransmission and mechanical efficiency at a molecule level 17,20 , and also, the decrease in vibration reduces the mechanical tissue stress. And about the influence of compression garments on metabolism, although some authors have not found any differences at an energetic level ${ }^{12}$ other groups $\mathrm{do}^{53}$. In our study we have found a reduction in the amount and severity of the histological muscle damage in the PT group, and after the statistical analysis we conclude that this reduction is because the use of the compression thighs.

The reduction in the amount and severity of muscle damage in the subjects of our study can be due to knee and hip ROM reduction, the decrease of muscular oscillation, to the direct effect of the compression on the muscle, or other factors (thermal effects, venous return, etc.), related to the use of compression garments, or a combination of several of them, further research is needed to clarify it.

DOMS is a common situation in sports practice with several signs and symptoms, but specially, with a reduction in force-generating capacity ${ }^{37}$, lasting from 4 days to several weeks ${ }^{54,55}$. We know that DOMS is not only a histological injury, but muscle function is considered to be a reliable and valid marker for the degree of muscle damage, and, theoretically as less histological damage, minor decrease in muscle function ${ }^{37}$.

Strength is essential for athletic performance, strength disturbances are a risk factor for muscle injury ${ }^{56}$, therefore, a garment protecting against a strength reducing injury, can be very useful.

\section{References}

1. Lieber RL, Fridén J. Morphologic and mechanical basis of delayed-onset muscle soreness. Journal of the American Academy of Orthopaedic Surgeons 2002; 10(1):67-73.

2. Armstrong R. Initial events in exercise-induced muscular injury. Medicine and science in sports and exercise 1990; 22(4):429.

3. Newham D, Mills K, Quigley B, Edwards R. Pain and fatigue after concentric and eccentric muscle contractions. Clinical science (London, England: 1979) 1983; 64(1):55.

4. Howell J, Chleboun G, Conatser R. Muscle stiffness, strength loss, swelling and soreness following exercise-induced injury in humans. The Journal of physiology 1993; 464(1):183-196.

5. Nikolaidis MG, Jamurtas AZ, Paschalis V, Fatouros IG, Koutedakis $Y$, Kouretas D. The effect of muscle-damaging exercise on blood and skeletal muscle oxidative stress: magnitude and time-course considerations. Sports Medicine 2008 38(7):579-606.

6. Nosaka K, Clarkson PM. Changes in indicators of inflammation after eccentric exercise of the elbow flexors. Medicine and science in sports and exercise 1996; 28(8):953.

7. Ebbeling CB, Clarkson PM. Exercise-induced muscle damage and adaptation. Sports medicine (Auckland, NZ) 1989;
7(4):207.

8. Friden J. Muscle soreness after exercise: implications of morphological changes. International journal of sports medicine 1984; 5(2):57.

9. Evans W, Meredith C, Cannon J, et al. Metabolic changes following eccentric exercise in trained and untrained men. Journal of Applied Physiology 1986; 61(5):1864-1868.

10. Cheung K, Hume PA, Maxwell L. Delayed onset muscle soreness: treatment strategies and performance factors. Sports Medicine 2003; 33(2):145-164.

11. Järvinen $T A$, Järvinen $T L$, Kääriäinen $M$, Kalimo $H$, Järvinen M. Muscle injuries biology and treatment. The American journal of sports medicine 2005; 33(5):745-64.

12. Trenell MI, Rooney KB, Carolyn M, Campbell S, Thompson $\mathrm{H}$. Compression garments and recovery from eccentric exercise: a 31P-MRS Study. Journal of sports science and medicine 2006; 5:106-114.

13. Bakken B. The Influence of Lower Body Compression Clothing on Markers of Running Economy During Submaximal Treadmill Running: Montana State University Bozeman 2011.

14. Bringard A, Perrey S, Belluye N. Aerobic energy cost and sensation responses during submaximal running exercise: Positive effects of wearing compression tights. International journal of sports medicine 2006; 27(5):373-378.

15. Burden RJ, Glaister M. The effects of ionised and non-ionised compression garments on sprint and endurance cycling. The Journal of Strength \& Conditioning Research 2011.

16. de Glanville KM, Hamlin MJ. Positive effect of lower body compression garments on subsequent $40-\mathrm{kM}$ cycling time trial performance. The Journal of Strength \& Conditioning Research 2012; 26(2):480.

17. Doan $B$, Kwon $\mathrm{Y}-\mathrm{H}$, Newton $\mathrm{R}$, et al. Evaluation of a lowerbody compression garment. Journal of sports sciences 2003; 21(8):601-610.

18. Eckert NR. Limb compression does not alter the forces generated during the vertical jump: Department of Kinesiology, Indiana University 2009.

19. Higgins T, Naughton GA, Burgess D. Effects of wearing compression garments on physiological and performance measures in a simulated game-specific circuit for netball. Journal of Science and Medicine in Sport 2009; 12(1):223226.

20. Kraemer WJ, Bush JA, Bauer JA, et al. Influence of Compression Garments on Vertical Jump Performance in NCAA Division I Volleyball Players. The Journal of Strength \& Conditioning Research 1996; 10(3):180-183.

21. Lovell DI, Mason DG, Delphinus EM, McLellan CP. Do compression garments enhance the active recovery process after high-intensity running? The Journal of Strength \& Conditioning Research 2011; 25(12):3264.

22. Sear JA, Hoare TK, Scanlan AT, Abt GA, Dascombe BJ. The effects of whole-body compression garments on prolonged high-intensity intermittent exercise. The Journal of Strength \& Conditioning Research 2010; 24(7):1901-1910.

23. Sperlich B, Haegele M, Achtzehn S, Linville J, Holmberg HC, Mester J. Different types of compression clothing do not increase sub-maximal and maximal endurance performance in well-trained athletes. Journal of sports sciences 2010; 28(6):609-614.

24. Davies V, Thompson KG, Cooper S-M. The effects of compression garments on recovery. The Journal of Strength \& Conditioning Research 2009; 23(6):1786.

25. Duffield R, Cannon J, King M. The effects of compression garments on recovery of muscle performance following highintensity sprint and plyometric exercise. Journal of Science and Medicine in Sport 2010; 13(1):136-140.

26. Gill N, Beaven C, Cook C. Effectiveness of post-match re- 
covery strategies in rugby players. British journal of sports medicine 2006; 40(3):260-263.

27. Kraemer WJ, Flanagan SD, Comstock BA, et al. Effects of a whole body compression garment on markers of recovery after a heavy resistance workout in men and women. The Journal of Strength \& Conditioning Research 2010; 24(3):804.

28. Montgomery PG, Pyne DB, Hopkins WG, Dorman JC, Cook $\mathrm{K}$, Minahan CL. The effect of recovery strategies on physical performance and cumulative fatigue in competitive basketball. Journal of sports sciences 2008; 26(11):1135-1145.

29. Sperlich B, Born D, Haegele M, Zinner C, Holmberg H-C. Effects of compression textiles on performance enhancement and recovery]. Sportverletzung Sportschaden: Organ der Gesellschaft für Orthopädisch-Traumatologische Sportmedizin 2011; 25(4):227.

30. Pearce AJ, Kidgell DJ, Grikepelis LA, Carlson JS. Wearing a sports compression garment on the performance of visuomotor tracking following eccentric exercise: A pilot study. Journal of Science and Medicine in Sport 2009; 12(4):500-502.

31. Houghton LA, Dawson B, Maloney SK. Effects of wearing compression garments on thermoregulation during simulated team sport activity in temperate environmental conditions. Journal of Science and Medicine in Sport 2009; 12(2):303309.

32. Bernhardt T, Anderson GS. Influence of moderate prophylactic compression on sport performance. J Strength Cond Res 2005; 19(2):292-297.

33. Fedorko BF. The Effects of Continuous Compression as a Therapeutic Intervention on Delayed Onset Muscle Soreness Following Eccentric Exercise: ProQuest; 2007.

34. Jakeman JR, Byrne C, Eston RG. Efficacy of lower limb compression and combined treatment of manual massage and lower limb compression on symptoms of exercise-induced muscle damage in women. The Journal of Strength \& Conditioning Research 2010; 24(11):3157.

35. Jakeman JR, Byrne C, Eston RG. Lower limb compression garment improves recovery from exercise-induced muscle damage in young, active females. European journal of applied physiology 2010; 109(6):1137-1144.

36. Kraemer WJ, Bush JA, Wickham R, et al. Influence of compression therapy on symptoms following soft tissue injury from maximal eccentric exercise. The Journal of orthopaedic and sports physical therapy 2001; 31(6):282.

37. Paulsen G, Mikkelsen UR, Raastad T, Peake JM. Leucocytes, cytokines and satellite cells: what role do they play in muscle damage and regeneration following eccentric exercise? Exercise Immunology Review 2012; 18:42-97.

38. Orozco-Levi M, Coronell C, Ramírez-Sarmiento A, et al. Injury of peripheral muscles in smokers with chronic obstructive pulmonary disease. Ultrastructural pathology 2012; 36(4):228-238.

39. Stauber W, Clarkson P, Fritz V, Evans W. Extracellular matrix disruption and pain after eccentric muscle action. Journal of Applied Physiology 1990; 69(3):868-674.

40. Shephard RJ, Rhind S, Shek PN. Exercise and the immune system. Sports Medicine 1994; 18(5):340-369.
41. Borràs X, Balius X, Drobnic F. Compression shorts effects in the hip range of motion and in vertical jump. Apunts de Medicina de l'Esport 2012; 47(173):31-36.

42. Nurenberg P, Giddings $C$, Stray-Gundersen J, Fleckenstein J, Gonyea W, Peshock R. MR imaging-guided muscle biopsy for correlation of increased signal intensity with ultrastructural change and delayed-onset muscle soreness after exercise. Radiology 1992; 184(3):865-869.

43. Orozco-Levi M, Gea J, Lloreta J, et al. Subcellular adaptation of the human diaphragm in chronic obstructive pulmonary disease. European Respiratory Journal 1999; 13(2):371-378.

44. Straub V, Rafael JA, Chamberlain JS, Campbell KP. Animal models for muscular dystrophy show different patterns of sarcolemmal disruption. The Journal of cell biology 1997; 139(2):375-385.

45. Jiang TX, Reid WD, Belcastro A, Road JD. Load dependence of secondary diaphragm inflammation and injury after acute inspiratory loading. American journal of respiratory and critical care medicine 1998; 157(1):230-236.

46. Artells R, Navarro A, Diaz T, Monzó M. Ultrastructural and Immunohistochemical Analysis of Intestinal Myofibroblasts During the Early Organogenesis of the Human Small Intestine. The Anatomical Record 2011; 294(3):462-471.

47. Malm C, Sjödin B, Sjöberg B, et al. Leukocytes, cytokines, growth factors and hormones in human skeletal muscle and blood after uphill or downhill running. The Journal of physiology 2004; 556(3):983-1000.

48. Gosker H, Kubat B, Schaart G, Van Der Vusse G, Wouters $\mathrm{E}$, Schols A. Myopathological features in skeletal muscle of patients with chronic obstructive pulmonary disease. European Respiratory Journal 2003; 22(2):280-285.

49. Agresti A. Categorical data analysis: Wiley-interscience; 2002.

50. McHugh MP, Connolly DA, Eston RG, Gleim GW. Exerciseinduced muscle damage and potential mechanisms for the repeated bout effect. Sports Medicine 1999; 27(3):157-170.

51. Borràs X, Balius X, Drobnic F. Effect of lower body compression garment in running mechanics. ISBS-Conference Proceedings Archive; 2011.

52. Borràs X, Balius X, Drobnic F, Til L, Turmo A, Valle J. Effects of lower body compression garment in muscle oscillation and tissular injury during intense exercise. ISBS-Conference Proceedings Archive; 2011.

53. Davies RC, Eston RG, Fulford J, Rowlands AV, Jones AM. Muscle damage alters the metabolic response to dynamic exercise in humans: a 31P-MRS study. Journal of Applied Physiology 2011; 111(3):782-790.

54. Clarkson PM, Tremblay I. Exercise-induced muscle damage, repair, and adaptation in humans. Journal of Applied Physiology 1988; 65(1):1-6.

55. Close GL, Ashton T, Cable T, et al. Ascorbic acid supplementation does not attenuate post-exercise muscle soreness following muscle-damaging exercise but may delay the recovery process. British Journal of Nutrition 2006; 95(5):976-981.

56. Freckleton G, Pizzari T. Risk factors for hamstring muscle strain injury in sport: a systematic review and metaanalysis. British journal of sports medicine 2013; 47(6):351358. 